unnecessary treatment and investigation for 9000 children per year across England and Wales.

\section{G97(P) ADOLESCENT OBESITY: EXPLORING THE HEALTH RELATED QUALITY OF LIFE IN HELP SEEKING OBESE ADOLESCENTS IN THE UNITED KINGDOM}

AR Rolle. Institute of Child Health, University College of London, London, UK

\subsection{6/archdischild-2018-rcpch.94}

Background According to previous studies, overweight and obesity in children and adolescents were associated with impaired health-related quality of life (HRQOL) and depression. The objective of this study is to describe the HRQOL and risk for depression in help seeking obese adolescents within the United Kingdom.

Methods This is a cross-sectional study conducted among 293 obese adolescents (13-18 years) attending the weight management clinic at the University College of London Hospital, England. The stratified cluster sampling framework was used; all participants were referred to this clinic by a general practitioner or paediatrician. Body Mass Index (BMI) was calculated using BMI z-score. The Paediatric Quality of Life Questionnaire (PedsQL) was used to measure HRQOL and The Short Mood and Feeling Questionnaire (SMFQ) was used to assess the likelihood of depression.

Results Study included 123 males and 170 females, mean BMI 43. Findings revealed that a higher quality of life (QOL) was found among younger adolescents, with lower QOL found among obese individuals. Female adolescents were found to score lower on emotional functioning and depression when compared with males, and adolescents who met the threshold for depression scored lower on all measures relating to QOL. The study population had a lower QOL of life when compared to healthy adolescents, and paediatric population with chronic diseases such as asthma, diabetes, and cancer.

Conclusion Compared with healthy adolescent population, the QOL in the study population was lower, and adolescents who met the threshold for depression had an overall lower QOL.

\section{Trainees session}

\section{G98 EXCEPTION REPORTING AT GREAT ORMOND STREET HOSPITAL - BUILDING ON JUNIOR DOCTORS EXPERIENCES}

${ }^{1} G L P$ Manning, 'D Das, 1J Hassell, 1,2E Parish, 'S Ottaway, 1,2J Poisson, 1,2S Sharma, ${ }^{1} \mathrm{R}$ McCulloch. ${ }^{1} J u n i o r$ Doctors Forum, Great Ormond Street Hospital, London, UK; ${ }^{2}$ Post Graduate Medical Education, Great Ormond Street Hospital, London, UK

\subsection{6/archdischild-2018-rcpch.95}

Aims The new English/Welsh Junior Doctor (JD) contract introduces a powerful tool for positive change - the Exception Report (ER). Following a staged introduction, ER has been available to all JDs (including those not in training), throughout Great Ormond Street Hospital (GOSH) since June 2017. Initial rates of ER have been low, with concerns of JD disillusionment. This project aims to improve the number of submitted ERs with secondary analysis of ER outcome.

Methods A process map identified primary drivers of reporting; Educational Supervisor (ES) engagement; and systemic change. Access to ER systems was improved by incorporating with the postgraduate medical education (PGME) smartphone app. ER was decoupled from ES by allocating departmental ER consultant leads. Ideas on local exception causes; barriers to reporting; and potential solutions were obtained from a JD focus group, which aided production of a guideline for ER leads to address ER root causes. After promoting ER at hospital induction, further interventions were targeted by surveying all JDs on personal experience of exceptions; ER processes; and opinions on reporting.

Progress was measured by graphing ER numbers, broken down by reporting department. Future change ideas included a PGME-led awareness campaign, including website, e-newsletter, $(\mathrm{P})$, video and podcast facets; publicity of previous work on JD perspectives; creation of a framework, targeted at JDs, encouraging junior-lead solutions when reporting; supplementation of PGME ES resources; and targeted signposting towards currently-available courses and learning resources.

Results 56 ERs were submitted during Mar-Sep 2017, leading to plans to redesign one department's rota, with financial compensation for three JDs in multiple departments. An additional fellow is being recruited into another department following a JD-initiated business case including, amongst other arguments, ER submissions. No fines have been levied. Multiple interventions are ongoing, with monthly plan-do-study-act (PDSA) cycles planned to aid continued improvement, and to ensure all JDs at GOSH feel empowered to submit ERs.

Conclusions ER should be used positively to identify system issues, and early usage at GOSH has demonstrated ER to both support and initiate constructive departmental change. Impact from current interventions is awaited, as departments harness the potential of the ER process.

\section{G99 SUPPORTING PAEDIATRIC TRAINEES INVOLVED IN MEDICO-LEGAL INVESTIGATIONS}

A Sammut, W Kelsall. Neonatal Intensive Care Unit, Cambridge University Hospitals NHS Foundation Trust, Cambridge, UK

\subsection{6/archdischild-2018-rcpch.96}

Aim Feedback from trainees highlighted different levels of support offered to trainees across the training programme. Many trainees have limited experience of Coroner's inquests, Court cases, GMC fitness to practice hearings, CQC visits, statement writing, serious incident investigations, Deanery and School of Paediatrics visits. More junior trainees have described these as stressful events. The aim of this study was to review the support offered to trainees and develop more consistent approaches.

Methods An online regional trainee survey was conducted between October 2016 and January 2017. This included 8 multiple choice questions with free text comments. Questions related to whether (1) trainees had been involved in such events during their training, (2) which trusts they worked in, (3) whether they received adequate support, and (4) what training if any, they had in these areas. The web link was sent to all trainees by the Paediatric Specialty Administrator and posted on the School Facebook Group.

Results A total of 40 paediatric trainees replied. 34 (85\%) reported previous involvement in such events: 20 (59\%) felt well supported by their hospital, 8 (24\%) felt that they needed support but that this was not offered or available locally and $6(17 \%)$ felt 
that they did not need support at the time. 35 (88\%) of Paediatric trainees had not received any formal training on how to deal with many of these situations. All respondents agreed that further training on dealing with these issues was as important as their clinical training in paediatrics.

Conclusion Whilst many paediatric trainees felt well supported when dealing these events, many were not. It was evident that the School had to provide more robust, uniform support to all trainees. Since the survey dedicated monthly management seminars have been established, a mentoring scheme has been launched and specific legal training days have been offered. Consultants willing to offer such support have been signposted to trainees.

\section{G100 FEEDBACK IN PAEDIATRICS: IDENTIFYING ATTITUDES, PERCEPTIONS AND BARRIERS TO HIGH QUALITY EDUCATIONAL FEEDBACK WITHIN REGIONAL PAEDIATRIC TRAINING}

${ }^{1} \mathrm{~L}$ Gabbott, ${ }^{2} \mathrm{E}$ Osmond, ${ }^{3} \mathrm{~A}$ Baverstock. ${ }^{1}$ Paediatrics, Great Western Hospitals, Swindon, UK; ${ }^{2}$ Neonatal Intensive Care Unit, St Michael's Hospital, Bristol, UK; ${ }^{3}$ Paediatrics, Musgrove Park Hospital, Taunton, UK

\subsection{6/archdischild-2018-rcpch.97}

Paediatrics as a speciality has previously been a red outlier for the feedback category within the annual GMC training survey. This suggests that trainees at least, feel that feedback within their training is insufficient.

We wished to assess perceptions of feedback and identify both real and perceived barriers to successful feedback by sampling current trainees and supervisors within the Severn Deanery on their experiences.

The topic was introduced at a workshop during the Severn Deanery Paediatric Conference in 2016. Copies of the trainee questionnaire were distributed and subsequently an online version was sent via deanery email and the Severn Paediatrics Facebook group. Trainers were surveyed via an online form disseminated via email. We had a response rate of $65 \%$ for the trainee survey and $40 \%$ for the trainers' survey.

$72 \%$ of trainees reported feeling that they did not receive enough feedback, with several recurring themes identified, including lack of time, workload and staff shortages. This was also reflected in the trainers' survey but additionally the perception of feedback was cited as an issue, with trainees not always able to recognise 'feedback' in more informal situations, leading to a mismatch between the amount trainers felt was given versus the amount trainees acknowledged.

$83 \%$ of trainees wanted feedback integrated into daily practice, however only $34 \%$ of trainers felt that daily feedback was necessary. There was concern over trainee resilience and the ability to give constructive feedback to trainees; 'It does seem 'unfair' when they are busting a gut to keep the show on the road to give them any kind of negative feedback', however a recurring theme from trainees was to reduce the perceived stress of feedback by increasing its regularity; ' I think this should be normalised, i.e. recognising that there are always things we could do better, it's not a criticism'.

The barriers we identified to regular feedback are well recognised within current medical training. However, our responses suggest a cultural issue within paediatrics regarding the perceived resilience of paediatric trainees. Our next step is to challenge the culture of feedback locally to improve clinical training within our region.

\section{G101 JUNIOR DOCTOR LED TRAINING TO IMPROVE THE QUALITY OF QUALITY IMPROVEMENT}

${ }^{1} \mathrm{P}$ Rees, ${ }^{1} \mathrm{~J}$ Wright, ${ }^{2} \mathrm{~V}$ Jones. 'Gastroenterology, North Middlesex University Hospital, London, UK; ${ }^{2}$ Paediatrics, North Middlesex University Hospital, London, UK

\subsection{6/archdischild-2018-rcpch.98}

Aims All junior doctors are expected to undertake quality improvement (QI). However formal coaching in QI methods, their theoretical underpinning and application, is sporadic. This combination of mandatory QI with a lack of training can result in projects lacking theoretical underpinning and correct use of established methodology that fail to measurably or sustainably improve care, further demoralising trainees. We hypothesised that improving trainees' QI capability would increase their use of formal QI methods and subsequently improve the quality of QI at our institution. A six-week training programme was delivered to junior doctors by a junior doctor. We aimed to increase junior doctors' confidence using and applying the model for improvement.

Methods Training was aimed at junior doctors at an inner-city District General Hospital but open to multi-disciplinary staff. Teaching mirrored the Cincinnati Children's Qi algorithm, underpinned by Deming's theory of profound knowledge. This covered the QI process using the Model for Improvement. Sessions were didactic, interactive and practical, using real-life examples and repetition. Training was evaluated using the Kirkpatrick model with: knowledge assessments, evaluation forms and follow-up surveys. Sessions were adapted according to feedback. On completion, participants received certificates for their portfolios, the option of further coaching, and access to a QI toolkit.

Results Training was attended by 83 multidisciplinary staff: largely junior doctors, pharmacists and paediatric nurses. Knowledge, mapped to session aims, demonstrably increased. Average knowledge scores increased from $48 \%$ to $72.5 \%$ in week 1: and from $27 \%$ to $62 \%$ in week 6 . On completion, $81 \%$ felt confident using the Model for Improvement; 95\% felt confident completing a QI project. We received positive feedback about training being junior doctor-led and about the training programme. After training: 95\% felt they saw quality and safety issues differently, 95\% felt they had acquired new knowledge or skills and $100 \%$ said they felt empowered to improve.

Conclusion Junior doctors appreciated and benefitted from formal QI training. Since training, there are several on-going QI projects at our institution using the Model for Improvement. We hope build on this success by integrating QI training into junior doctors' curriculum at our hospital to further improve QI capability within this cohort of future leaders.

\section{G102 TOO MANY TWEETS, DON'T LIKE TO LIKE OR JUST LOST THE THREAD? THE HUB - A SINGLE PLATFORM FOR TRAINEE COMMUNICATION}

${ }^{1,2} \mathrm{~A}$ Lelliott, ${ }^{1,2} \mathrm{C}$ Holland, 1,2E Ambrose. 'ST4-8 Trainee Committee, Oxford School of Paediatrics, Oxford, UKi ${ }^{2}$ Children's Services, Oxford University Hospitals NHS Foundation Trust, Oxford, UK

\subsection{6/archdischild-2018-rcpch.99}

Aims Communication is key in healthcare, with poor communication linked to patient dissatisfaction and complaints. We believe that effective communication is equally important for 